\title{
Structural health and dynamic behavior of residential buildings: field challenges in the rehab of damaged reinforced concrete
}

\author{
M. S. Chalhoub ${ }^{1}$ \\ ${ }^{1}$ Notre Dame University, Department of Civil and Environmental Engineering, Louaize, Lebanon
}

\begin{abstract}
Reinforced concrete buildings require special consideration under dynamic excitations due to their anisotropic material properties. Strain compatibility equations are used in concrete analysis and design with assumptions about the stress and strain field across member section and member length. However, these assumptions fall short of describing real life behavior when concrete elements deteriorate, age or undergo cyclic loading. This paper addresses the structural health of reinforced concrete buildings and proposes an analytical model to account for concrete damage through loss of bond. The proposed model relates steel loading that causes bond distress to design parameters such as development length and bar properties, and therefore could be complemented by field measurement. The paper proposes a diagnosis method and discusses the sustainability of the structure by assisting in a simplistic decision rule as to whether to perform minor fixes, major rehabilitation, or disposal. Emphasis is placed on the difference between reversible and irreversible effects of cyclic loading on structural behaviour, and draws a distinction between damage to the girder and damage to the column in the overall structural system. The model is compared to empirical results to address field challenges faced when the structure is subjected to severe conditions in its ambient environment, or to unusual loading. Deterioration in concrete causes alteration in its composite behavior with the reinforcing steel. This affects the fundamental period of the structure, and its response to seismic loading.
\end{abstract}

\section{Introduction}

Reinforced concrete (RC) construction constitutes the majority of residential buildings in many countries for reasons related to availability of materials, local expertise, and affordability [1]. From a serviceability and sustainability perspective, concrete minimizes noise and vibration transfer, and has advantages in terms of fire protection and thermal characteristics in comparison to other structural materials [2]. From a strength perspective, it offers a reasonable efficiency for low- and medium-rise buildings. Reinforced concrete was also extensively used for high rise construction for most of the twentieth century [3]. Alongside the advantages of concrete, there are shortcomings related to environmental impact, especially at its manufacturing stages $[4,5]$.

Reinforced concrete requires special assumptions due to its anisotropic and non-homogeneous properties. Most RC member design procedures involve simplifying assumptions of strain compatibility to reach coherent calculation procedures for beam flexure, column axialflexural interaction equations, and other design formulas [6]. Depending on several factors including initial mix design, placement quality, or operational loads, strain compatibility may not remain applicable throughout the lifetime of the building. Research literature addressed concrete aging and its effect on overall structural performance $[7,8]$. Other studies addressed steelconcrete bond theoretically and experimentally and found that it has a great effect on RC member behavior. Early research on bond comprised straight pull out tests that confirmed a significant change in capacity with deterioration of bond $[9,10]$.

\section{Effect of steel-concrete bond}

\subsection{Localized vs. member level bond effects}

The bond between reinforcing steel and concrete governs the transfer of stress between these two materials. A distinction should be drawn between bond at the localized stress field level, and bond at the RC member level. The first category addresses the micro-structure interface whereby the concrete is crushed by the steel lug edge [11, 12]. The second category addresses the cumulative effects of rebar pull-out causing excessive rotation at beam-column joints or crack formation in the tension zone $[13,14]$. Cyclic loading causes alternation between tension and compression at the same member location, and therefore requires the investigation of reversal of member forces computed from static analysis. 


\subsection{Bond deterioration at the local bar level}

Bond requires development length. If bond resistance deteriorates, reinforcing bars are likely to slip and destroy the steel-concrete composite action. A severe loading such as impulse or earthquake may cause brittle failure. Therefore, bond has multiple functions including overall strength and ductility. It is affected by many factors including concrete cover, rebar spacing, bundling, and position. Depending on the manufacturer, certain bars have ribs at an angle that influences bond and pull-out behaviour. It was shown that for the same configuration, bond resistance to straight pull-out is greater under dynamic loading than it is under static loading [15]. This conclusion may not hold under dynamic cyclic loads.

Research showed that bond strength decreases as bar diameter increases. This conclusion shed light on the selection of reinforcing steel in practical design, following the determination of a total required steel area [16]. For example a choice of \#9 versus \#6 bars would not only be affected by placement, but also by increasing the contact surface, or the frictional interface. In this case, smaller bar diameters would be favored, all other design parameters being equal.

Development length of bars was also studied with the effect of confinement. Other factors being constant, ultimate bond stress varies as a function of $f_{c}^{\prime}$ because it is related to concrete tensile strength [17]. From traditional tri-axial stress relationships, confinement causes an increase in $f_{c}^{\prime}$ and provides larger normal stress between steel and concrete.

Rebar placement, spacing, member width and anchorage also affect bond strength in terms of concrete splitting failure [18]. Studies considering a variety of deformed bar surface properties established a relationship between concrete cracking and slippage along the embedment length. Results helped formulate resistance to pull-out along embedment length [19]. Related research showed that since confinement increases normal stress around the bar, it has a significant effect on bond [20].

\subsection{Bond slip effects at the member level}

The cumulative effects of localized bond slip result in overall drop in performance at the RC member level. In particular, beam-column joints would undergo additional rotation beyond the level captured by linear elastic analysis [21]. Once reinforcing steel starts to move relative to concrete, the members connected at the joints go through additional rotation relative to each other. Areas in the vicinity of beam-columns joints in momentresisting frames subjected to dynamic loading are affected the most [14]. This result is expected because the energy imparted into the superstructure by the earthquake is dissipated through ductile behavior at the joints [22].

\section{Model Development}

\subsection{Mathematical derivation}

We develop a mathematical model that represents the bond slip behavior. Consider the ring of concrete in touch with the bar in between two consecutive lugs. Denote by $\sigma$ the normal stress exerted by the lug on the concrete. Consider the lug as having an angle $\theta$ with the longitudinal axis of the rebar where $45^{\circ} \leq \theta \leq 90^{\circ}$. Let $d_{b}$ denote bar diameter and $t_{l}$ the height of the lug above the steel surface. The area on the wedge of the steel lug concentric to the bar axis is:

$$
A_{o}=\frac{\pi}{4}\left[\left(\frac{2 t_{l}}{\sin \theta}+d_{b}\right)^{2}-d_{b}^{2}\right]
$$

For an embedment length $l_{d}$, the resultant is:

$$
R_{o}=\sigma \sin \theta \pi t_{l}\left(t_{l}+d_{b}\right) \frac{l_{d}}{s}
$$

The projected lug area concentric to the rebar axis is:

$$
A_{t}=\pi\left[t_{l}+d_{b}\right] \frac{t_{l}}{\tan \theta}
$$

The component of $\sigma$ exerted on this area contributes to concrete splitting effect. Its resultant is:

$$
\begin{aligned}
R_{t} & =\sum_{l_{d}} \sigma \cos \theta \pi\left[t_{l}+d_{b}\right] \frac{t_{l}}{\tan \theta} \\
R_{t} & =\sigma \cos \theta \pi\left[t_{l}+d_{b}\right] \frac{t_{l}}{\tan \theta} \frac{l_{d}}{s}
\end{aligned}
$$

The concrete shear area adjacent to the lug is:

$$
A_{c v}=\pi\left[2 t_{l}+d_{b}\right]\left[\frac{2 t_{l}}{\tan \theta}+s\right]
$$

If $f_{c v}$ is the concrete shear strength, shear resistance is:

$$
\begin{aligned}
R_{c v} & =\sum_{l_{d}} f_{c v} \pi\left[2 t_{l}+d_{b}\right]\left[\frac{2 t_{l}}{\tan \theta}+s\right] \\
R_{c v} & =f_{c v} \pi\left[2 t_{l}+d_{b}\right]\left[\frac{2 t_{l}}{\tan \theta}+s\right] \frac{l_{d}}{s}
\end{aligned}
$$

The area of an infinitesimal element around the circumference of the steel segment within the clear spacing of two consecutive lugs is:

$$
d A_{c}=\frac{d_{b}}{2} d \alpha d x
$$


Where $d \alpha$ is an infinitesimal angle about the rebar centroid, and $d x$ is an infinitesimal distance parallel to the longitudinal rebar axis. Among the range of deformed bar patterns, the simplest pattern has lugs that are parallel to each other, spaced at about $1 / 2$ " to 1 " and orthogonal to the bar axis.

To express the frictional resistance mathematically, we consider that the confinement stress, denoted $f_{1}^{\prime}$ contributes to frictional resistance to motion, at both the concrete-concrete interface and the steel-concrete interface. Denote $\mu$ the friction coefficient, which depends on the pull-out displacement rate, $\dot{x}=d x / d t$, and on the angular location around the rebar periphery, $\alpha$. The differential force due to friction can be expressed as:

$$
d R_{s}=\mu(\dot{x} \alpha) f_{1}^{\prime}\left(\frac{d_{b}}{2}\right) \cdot d \alpha \cdot d x
$$

The resultant is a double integral over $\alpha$ and $x$, over the inter-lug segment, summed over the embedment length:

$$
R_{s}=\sum_{l_{d}} f_{1}^{\prime} \frac{d_{b}}{2} \int_{0}^{2 \pi} \int_{0}^{s} \mu(\dot{x}, \alpha) d \alpha \cdot d x
$$

The inclusion of $\alpha$ in the expression of $\mu$ is due to the fact that there may be localized imperfections around the rebar such as air pockets, or a large aggregate instead of bonding mortar, which may cause an uneven frictional resistance around the circumference of the bar. Such local imperfections and their effects can be accounted for separately through a safety reduction factor related to concrete mix and placement quality. As for the relative pull-out displacement rate or velocity range expected at incipient bond slip, we consider that the steel-concrete friction coefficient is constant along the embedment length. Applying these two simplifications to expression (11), performing double integration, and summing over the development length, we have:

$$
R_{s}=\pi \mu f_{1}^{\prime} d_{b} l_{d}
$$

The derivation sheds light on the difference between reversible and irreversible effects of loading. For a steel bar whose strength exceeds the bond slip load level, the effect is considered reversible. However, if bond slip occurs at a load level below the development of the bar strength the effect becomes irreversible.

\subsection{Application to Static Equilibrium}

The stress resultants in expressions (2), (5), (8), and (12) can be used in equilibrium equations in the longitudinal direction. As discussed earlier, (2), (5), and (12) could be extended into a dynamic equilibrium where the rate of change of the friction coefficient, inertia effects, and other related factors, are accounted for. However, the dynamic equilibrium is treated under a separate scope. Several cases could be identified, which we simplify under two main conditions that are most relevant to our scope. Case 1 pertains to the rebar reaching its full development function, while Case 2 corresponds to a pull-out prior to reaching yield. An optimal equilibrium would be reached under strength and economic conditions simultaneously. Denoting by $T_{s}$ the tensile force applied to the bar:

$$
T_{s}=A_{s t} f_{s}
$$

where $A_{s t}$ is a single bar steel section and $f_{s}$ is the stress applied to that section. If there is no bond slip, we have:

$$
T_{s}=A_{s t} f_{s} \leq R_{o}+R_{s}
$$

Otherwise, the bar would pull-out under the applied section stresses. In this case, we have:

$$
T_{s}=A_{s t} f_{s} \quad \geq R_{c v}
$$

Once the concrete shear resistance fails at the envelope layer, both the lug resistance and the frictional resistance along the steel segment between the lugs no longer contribute to bond. Research on steel-concrete friction coefficients shows that their values vary between 0.47 and 0.7 depending on finishing parameters and other factors [23, 24]. For the purpose of the present illustrative examples, we use 0.5 .

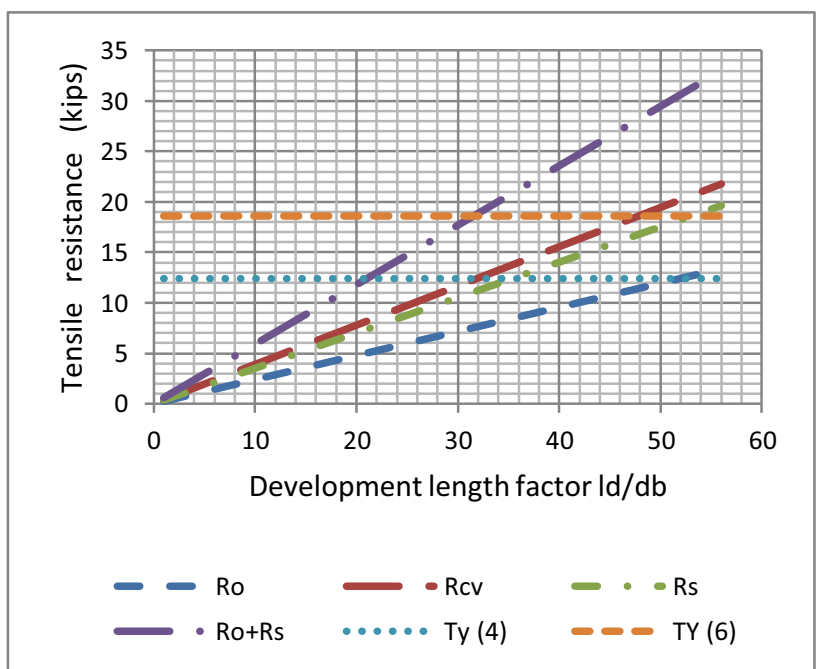

Figure 1. Bond and frictional tensile resistance vs. development length factor for No. 5 deformed bar in 4000 psi concrete.

The relationship between bar tensile force and bond resistance for a No. 5 bar in 4000 psi compression strength concrete is shown in Figure 1, where tensile resistance is plotted against development length factor. Yield forces in the bar are $\mathrm{T}_{\mathrm{y}}(4)=12.4 \mathrm{k}$ and $\mathrm{T}_{\mathrm{y}}(6)=18.6 \mathrm{k}$ for $f_{y}=40 \mathrm{ksi}$ and $f_{y}=60 \mathrm{ksi}$, respectively. Development length required by ACI is $37 d_{b}$, for $f_{y}=40 \mathrm{ksi}$, and $57 d_{b}$ for $f_{y}=60 \mathrm{ksi}$. For both $f_{y}$ values, inequality (14) is satisfied and the bar will yield before reaching the pull-out limit. However, shear strength in the concrete in the vicinity of 
the bond area is enough to carry the bar to yield for $f_{y}=40$ $\mathrm{ksi}$, but bond slip will occur before the bar yields for $f_{y}=60 \mathrm{ksi}$ (Figure 1). A similar analysis could be performed for various bar diameters, concrete compressive strength, and steel yield stress.

\section{Effect on Overall Structural Health}

\subsection{Effect of Bond Deterioration}

Bond deterioration has a significant effect on local critical zones, and it has an influence on the overall structural behavior, especially when subjected to dynamic loading. The additional rotation at the joints due to bond slip exhibits hysteresis behavior represented by a nonlinear curve $[21,22]$. The force-deformation curve starts with a straight line over the elastic range, then reaches a plateau where the joint rotates at no additional moment. When load reversal occurs, the joint starts rotating in the opposite direction while engaging the bar in friction until it bears against concrete. At that point, the bar on the opposite side of the beam starts its pulling cycle. Theoretically, reversal exhibits equal and opposite values. But if decay is included in the model, cycle $i+1$ will exhibit deterioration with respect to cycle $i$, until collapse of the joint, should the cyclic load continue.

\subsection{Effect of Aging}

Aging of concrete is one of the most determining phenomena in the behavior of structures. There are no standardized direct experimental processes to deliberately age concrete and test it on that basis. For this reason, the most reliable lab for aging would be the outdoors real life situation in cities where reinforced concrete constitutes the vast majority of buildings.

Data collected in various cities in Lebanon was compiled by building age, condition, and ambient environmental effects. A subset of 140 buildings was studied analytically. But coring and compressive strength tests were performed on only 5 buildings that were considered as representative of the others in the sample. The 5 buildings are not statistically significant, but their results were within a coherent range and therefore provided an indication of the state of the concrete in these older buildings. Some of the cylinders gave a compressive strength as low as 790 psi. The detailed field-related experiments were left outside the scope of this paper as a subject of future research [25].

\subsection{Effect of Design and Placement Quality}

Mix and structural design, and placement quality are very important and have a direct relationship with the two features above; bond deterioration and aging. Concrete that is well proportioned has a superior longevity to concrete that is not. Structural systems that are designed to withstand dynamic loading defined by code, will obviously perform better than the ones that are not. Some of the field challenges that we encountered had to do with all three components; mix, design, and placement. In the present paper, we mention some of those challenges as they cannot be fixed retroactively, but we shall rather provide a rational approach for decisionmaking in terms of types of actions that could be taken.

A challenge in many less developed countries is the lack of code guidelines. Another challenge is the poor or lack of supervision. Even when designed per European or US codes, the execution leaves room for mismanagement of resources and potential mishaps during construction.

\subsection{Remediation choices}

Although extensive research on $\mathrm{RC}$ damage caused by bond deterioration was performed in the 1960s, interest in bond effects for both steel and fiber reinforced concrete resurged in later decades as seismic codes grew more stringent [26, 27].

For existing buildings, parameters needed to perform calculations may not be easily available. To determine $f_{c}^{\prime}$ in an older building, coring and testing may be performed. But results from various parts of the same building may exhibit a large spread [25]. A simpler decision rule involves the overall state of the building. Table 1 provides a set of inspection results, with possible solutions. Three categories are defined for strength, serviceability, and aesthetic requirements (Table 1).

\begin{tabular}{|c|c|c|}
\hline Damage categories & Potential causes & Reversibility \\
\hline $\begin{array}{l}\text { Concrete cover } \\
\text { spalling }\end{array}$ & $\begin{array}{l}\text { Under-designed } \\
\text { cover } \\
\text { Mild rebar corrosion }\end{array}$ & $\begin{array}{l}\text { Uncover, treat bars, } \\
\text { provide new cover }\end{array}$ \\
\hline $\begin{array}{l}\text { Chunking around } \\
\text { bars }\end{array}$ & $\begin{array}{l}\text { Stress exceeds design } \\
\text { stresses } \\
\text { Severe corrosion }\end{array}$ & $\begin{array}{l}\text { Remove, track } \\
\text { damage, rebar } \\
\text { implants, re-cast }\end{array}$ \\
\hline $\begin{array}{l}\text { Localized steel } \\
\text { corrosion stains }\end{array}$ & $\begin{array}{l}\text { Lack of vibration } \\
\text { during placement } \\
\text { Hairline cracks; air, } \\
\text { water, chemicals } \\
\text { reach bars }\end{array}$ & $\begin{array}{l}\text { Uncover, treat bars, } \\
\text { provide new cover }\end{array}$ \\
\hline $\begin{array}{l}\text { Fluffy plaster, } \\
\text { caulking, or paint }\end{array}$ & $\begin{array}{l}\text { Damage } \\
\text { humidity } \text { or water } \\
\text { seepage }\end{array}$ & $\begin{array}{l}\text { Uncover, treat bars, } \\
\text { provide new cover }\end{array}$ \\
\hline $\begin{array}{l}\text { Large structural } \\
\text { cracks and visible } \\
\text { deflections }\end{array}$ & Bond deterioration & $\begin{array}{l}\text { Fix depends on } \\
\text { localized damage } \\
\text { Inject bond agent, } \\
\text { cast shadow member } \\
\text { Alternative solutions } \\
\text { involve exterior wrap }\end{array}$ \\
\hline $\begin{array}{l}\text { Beam-column joint } \\
\text { slack }\end{array}$ & $\begin{array}{l}\text { Bond deterioration } \\
\text { Bar pull-out } \\
\text { Fatigue, distress }\end{array}$ & $\begin{array}{l}\text { Building may pose } \\
\text { hazard in the } \\
\text { following event. } \\
\text { Consider disposal. }\end{array}$ \\
\hline $\begin{array}{l}\text { Structure exhibiting } \\
\text { misalignment or } \\
\text { leaning out-of-plumb }\end{array}$ & $\begin{array}{l}\text { Bond deterioration } \\
\text { Major loss of } \\
\text { strength }\end{array}$ & Dispose \\
\hline
\end{tabular}

\section{Effect on Dynamic Behavior}

\subsection{Effect on Fundamental Period}

Studies conducted on beam-column assemblages attempted to cast complex dynamic behavior in formulas. Approaches proposed in literature account for bond slip effect on overall structural dynamic behavior [21, 28].

To get a preliminary result on dynamic performance, consider a single bay and three degrees of 
freedom, one translation $u_{l}$ and two rotations at the joints, $u_{2}$ and $u_{3}$, respectively. We have:

$$
\begin{aligned}
& {\left[\begin{array}{lll}
k_{11} & k_{12} & k_{13} \\
k_{21} & k_{22} & k_{23} \\
k_{31} & k_{32} & k_{33}
\end{array}\right]\left[\begin{array}{l}
u_{1} \\
u_{2} \\
u_{3}
\end{array}\right]=\left[\begin{array}{c}
f_{e} \\
0 \\
0
\end{array}\right]} \\
& k_{11}^{*} u_{1}=f_{e}
\end{aligned}
$$

where $k_{11}^{*}$ condenses the $k_{i j}$ stiffness coefficients ( $i=1$, 2, 3; and $j=1,2,3 ; i \neq 1$, and $j \neq 1$ ) and $f_{e}$ is the elastic force. The mathematical derivation is under separate scope to focus here on the practical formulas for designers [25]. We define a girder-column stiffness ratio:

$$
\varphi=\frac{E_{c g} I_{g} L_{c}}{E_{c c} I_{c} L_{g}}
$$

where $E_{c g}$ and $E_{c c}$ are the moduli of elasticity for the concrete in the girder and in the column respectively, $I_{g}$ and $I_{c}$ are the moments of inertia of the girder and column respectively, and $L_{g}$ and $L_{c}$ are the span of the girder and column height respectively. We have:

$$
k_{11}^{*}=\frac{E_{c c} I_{C}}{L_{c}^{3}}\left(\frac{a+b . \varphi}{c+d . \varphi}\right)
$$

where $a, b, c$, and $d$, are constants that depend on column and girder properties [25]. Degradation in girder-column stiffness ratio is denoted by $\delta \varphi$. The drop in the condensed stiffness term differs whether the deterioration is occurring in the girder or the column. In both cases, however, it results in a significant drop in natural frequencies of the structural system. Figure 2 shows the drop in stiffness due to degradation in the girder, while Figure 3 shows results for degradation in the column.

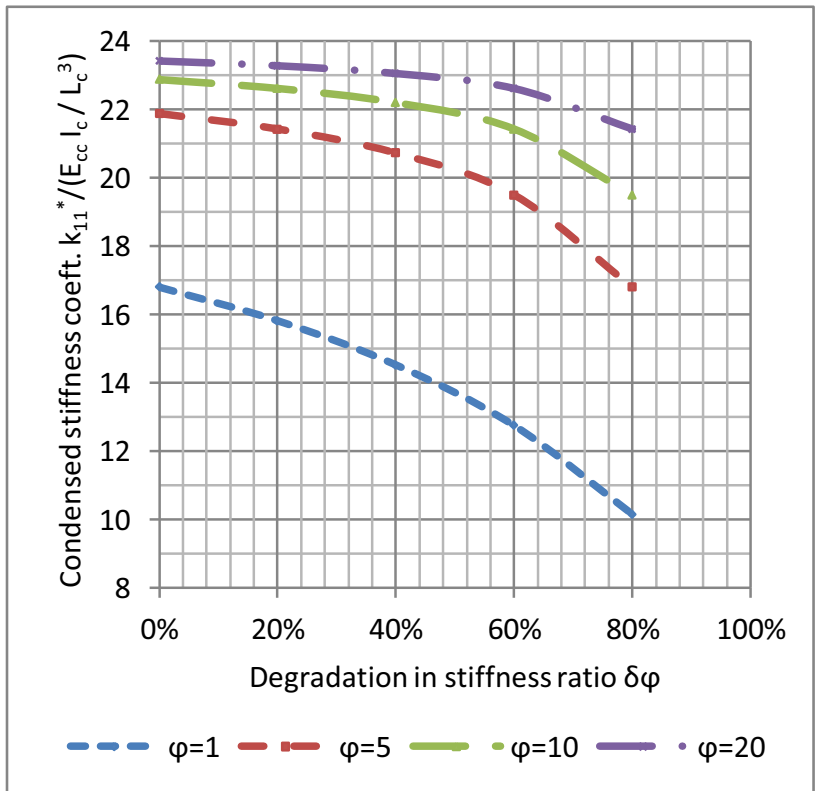

Figure 2. Drop in condensed stiffness as a function of deterioration in the girder moment of inertia.
For a stiffness ratio of 5 that decreases $60 \%$ through deterioration of girder moment of inertia, the condensed stiffness drops from 22 to 19.5. While for the same stiffness ratio, 5, that decreases $60 \%$ through deterioration of column moment of inertia, the condensed stiffness drops from 22 to 9 (Figure 3). These numerical examples support the strong column weak girder approach in the seismic design of RC structures.

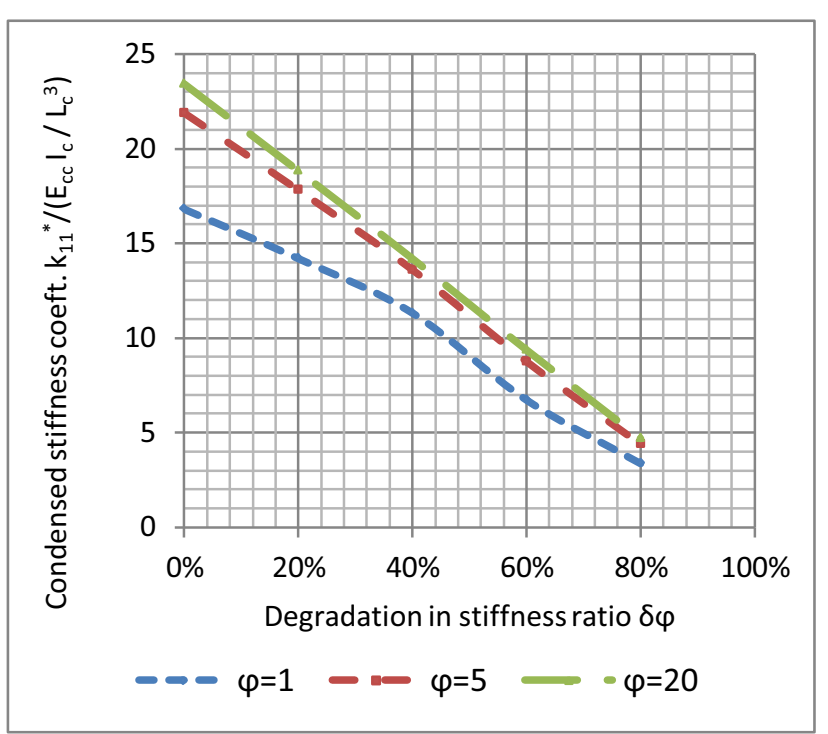

Figure 3. Drop in condensed stiffness as a function of deterioration in the column moment of inertia.

The results can be related to linear elastic structural analysis. For a free standing cantilever column whose top joint is allowed to rotate and translate without any restraints, the generic lateral stiffness coefficient is $3 E I / L^{3}, E, I$ and $L$ being the modulus of elasticity, moment of inertia, and span, respectively. For a column whose tip is not allowed to rotate, but is allowed to translate horizontally, the lateral stiffness coefficient is $12 E I / L^{3}$. For a portal, the first case results in a coefficient of 6 ; and the second case a coefficient of 24 . Therefore the worst case scenario of girder failure comprises bond deterioration in the girder at the column face, leaving the joint in the column to rotate freely. The worst case scenario of column failure through bond deterioration would be a hinge in the column leading to collapse, which is unacceptable form a RC design perspective.

\section{Conclusions}

Strain compatibility equations that are used in concrete analysis and design do not necessarily hold throughout the life of the RC member or structure. These assumptions become less applicable to real life behavior when concrete elements age or undergo cyclic loading. A model is developed to analyze the structural health of RC buildings taking into consideration concrete damage through loss of bond. The analytical model relates steel loading that causes bond distress to design parameters such as development length and bar properties, and could 
be complemented by field measurements in future research. The paper presents a diagnosis method and discusses the sustainability of the structure whether to perform minor fixes, major rehabilitation, or disposal. The model calls for a differentiation between girder damage and column damage in the context of reversibility. Empirical results were partially used and discussed in terms of field challenges faced when the structure is subjected to severe conditions in the ambient environment, or to unusual loading. Numerical applications of the analytical model developed in this paper support the strong column weak girder RC design.

\section{References}

1. T. R. Naik, "Sustainability of Concrete Construction," ASCE Practice Periodical on Structural Design and Construction, vol. 13, No. 2, pp. 98-103 (2008).

2. European Concrete Platform, "Sustainable Benefits of Concrete Structures," Ed. J. B. Jacobs, Brussels, Belgium, February (2008).

3. M. P. Collins, "In Search of Elegance: The Evolution of the Art of Structural Engineering in the Western World," Concrete International, vol. 23, No. 7, July, American Concrete Institute, pp. 55-72 (2001).

4. B. M. Damineli, F. M. Kemeid, P. S. Aguiar, and V. M. John, "Measuring the Eco-efficiency of Cement Use," Cement and Concrete Composites, vol. 32, No. 8, pp. 555-562, (2010).

5. P. K. Mehta, "Global Concrete Industry Sustainability," Concrete International, February (2009).

6. American Concrete Institute, ACI Committee 318, "Building Code Requirements for Structural Concrete and Commentary," ACI 318-11, (2011).

7. J. Gulikers, "Pitfalls and Practical Implications in Durability Design of reinforced Concrete Strutures," Proceedings of the 4th International RILEM PhD Workshop on Advances in Modeling Concrete Service Life, Madrid, Spain, November (2010).

8. U.S. Department of the Interior Bureau of Reclamation, "Materials Properties Model of Aging Concrete," Technical Service Center, Denver Colorado, (2005).

9. Z. Shi. Crack Analysis in Structural Concrete: Theory and Applications. Elsevier (2009).

10. Y. Hunaiti, "Aging Effect on Bond Strength in Composite Sections," ASCE Journal of Materials in Civil Engineering, vol. 6, No. 4, pp. 469-473 (1994).

11. Y. Goto, "Cracks Formed in Concrete around Deformed Tension Bars," ACI Journal, vol. 68, No. 2, pp. 244-251 (1971).

12. L. A. Lutz, "Analysis of Stresses in Concrete near a Reinforcing Bar Due to Bond and Transverse Cracking," ACI Journal Proceedings, vol. 67, No. 10, pp. 778-787 (1970).

13. R. H. Scott, and P. A. T. Gill, "Short-Term Distributions of Strain and Bond Stress along Tension Reinforcement," The Structural Engineer, vol. 65B, No. 2, pp. 39-48 (1987).
14. F. C. Filippou, E. P. Popov, and V. V. Bertero, "Modeling of Reinforced Concrete Joints under Cyclic Excitations," ASCE Journal of Structural Engineering, vol. 109, No. 11 (1983).

15. R. J. Hansen, and A. A. Liepins, "Behavior of Bond in Dynamic Loading," ACI Journal, pp. 563-583 (1962).

16. R. G. Mathey, and D. Watstein, "Investigation of Bond in Beam and Pullout Specimens with HighYield Strength Deformed Bars," ACI Journal, T. No. 57-50, pp. 1071-1089 (1961).

17. P. M. Ferguson, I. Robert, and J. N. Thompson, "Development Length of High Strength Reinforcing Bars in Bond," ACI Journal, T. No. 59-17, pp. 887922 (1962).

18. P. M. Ferguson, J. E. Breen, and J. N. Thompson, "Pull Out Tests on High Strength Reinforcing Bars," ACI Journal, T. No. 62-55, pp. 933-950 (1966).

19. H. H. Abrishami, and D. Mitchell, "Simulation of Uniform Bond Stress," ACI Materials Journal, vol. 89, No. 2, pp. 161-168 (1992).

20. L. J. Malvar, "Bond of Reinforcement under Controlled Confinement," ACI Materials Journal, vol. 89, No. 6, pp. 593-601 (1992).

21. E. Spacone, F. C. Filippou, and F. F. Taucer, "Fiber Beam-Column Model for Non-Linear Analysis of R/C Frames, Part 1: Formulation," Earthquake Engineering and Structural Dynamics, vol. 25, No. 7, pp. $711-725$ (1996).

22. Z. P. Bazant, and P. D. Bhat, "Prediciton of Hysteresis of Reinforced Concrete Members," ASCE Journal of the Structural Division, vol. 103, No. ST1 Jan. 1977.

23. B. G. Rabbat, and H. G. Russel, "Friction Coefficient of Steel on Concrete or Grout," ASCE Journal of Structural Engineering, vol. 111, No. 3, pp. 505-515 (1985).

24. P. Baltay, and A. Gjelsvik, "Coefficient of Friction for Steel on Concrete at High Normal Stress," ASCE Journal of Materials in Civil Engineering, vol. 2, No. 1, pp. 46-49 (1990).

25. M. S. Chalhoub, "Seismic Design and Dynamic Response of Reinforced Concrete Buildings with the Effects of Deterioration," working paper, CEM Rep. No. 02-2014 (2014).

26. M. G. Lee, C. T. Chiu, and Y. C. Wang, "The study of Bond Strength and Bond Durability of Reactive Powder Concrete," Journal of ASTM International, vol. 2, No. 7, July (2005).

27. H. Banon, J. M. Biggs, and H. M. Irvine, "Seismic Damage to Reinforced Concrete Frames," ASCE Journal of the Structural Division, vol. 107, No. ST9, Sep. (1981).

28. K. Emori, and W. C. Schnobrich, "Inelastic behavior of Concrete Frame-Wall Structures," ASCE Journal of the Structural Division, vol. 107, No. ST1, (1981). 